\title{
The Interaction between Media Using and Cognitive Style
}

\author{
Guibao Liu \\ College of Psychology and Education, Zaozhuang University, Zaozhuang Shandong, 277100, China
}

Keywords: media using; individual cognitive style

\begin{abstract}
As a kind of behavior pattern, individual cognitive style should affect the media using, then will the media using affect individual cognitive style? Taking college students as the object, this paper investigated their habits of media using and the relationship between media using and individual cognitive style. The survey found that there is apparent association between cognitive style and media using. Some volunteers tried to use more types of media, and we found it difficult to change the individual cognitive style, but can affect the habits of individual media using, and improve the efficiency to solve a problem by using different media. This conclusion provides a psychological support for the using of multimedia in education and communication.
\end{abstract}

\section{Introduction}

In everyday life, we often have this experience: for one thing, such as "can the salt protect the individual from the hazards of radioactive material? Different people have different ways to find the answer. some people find someone else to inquire about it, some people rush to buy the newspaper of today, some people rush to turn on the TV, while others are accustomed to listening to the radio, the internet is the best choice for most of young people, which includes part of the mobile internet. This reflects that the people are different in the individual cognitive style. They tend to choose certain ways to get the information and learning. For different question or learning needs, the way to get information through learning choice is basically the same. Why is it so?

Someone select a media and use it in Learning and entertainment, which we call it as the media using. Discussed in this article only the media using of learning, another paper will discuss the entertainment and games. The tendency which is manifested in the ways and methods in knowledge learning which we call it as the individual cognitive style, media selection is an important part of it.

American psychologist Hermann Witkin puts people into three type by individual cognitive style: field independence, field dependence and field mixed. Embedded Figure Test is an effective means to distinguish individual cognitive style.

Rule of thumb, we can feel that it has complicated relationship between the media using and individual cognitive style, but what is the specific contact between them? It is worthy of further exploration in the coexistence of multi-media today, if we clearly understand the relationship between them, it will affect our response to some common problems, such as how to make better use of media in teaching, how to deal with the game addicted from the breakthrough of individual psychological characteristics, etc.

\section{Research Process}

With experience, we can understanding it blurry that they affect each other gradual deepening between media using and individual cognitive style, until the formation of a given type of process. But such inference is clearly unconvincing.

This study selected the students in Zaozhuang University as the object, using the method of sampling survey, aimed to explore the relationship between media using and individual cognitive style in this special group. Then we selected 12 volunteers changing their media using: 6 field dependence, 6 field independence.in order to investigate could the changes of media using affect the 
individual cognitive style.

\subsection{Survey Sample Determination}

We promoted our research through posters, leaflets, campus BBS, micro blog, micro credit, the campus radio and theme activities, in order to call research object. There were 1632 people enrolled in the investigation, spanning the humanities, science and technology, art and education discipline.

Using the Embedded Figures Test for these people, selected 320 typical field dependent subjects and 320 typical field independent subjects. They were divided into two groups, A group is field dependent, $\mathrm{B}$ group is field independent.

\subsection{The Implementation of Questionnaire Survey}

The questionnaire was disigned for the four most common media: newspapers, radio, television and network. It was different in the degree of user's participation. when looking for a news or solving a problem, the order of media using may be different, either.

The question in our questionnaire was: when looking for a news or solving a problem, what is the order of media using.

Two groups of people arranged the questionnaire at the same time, statistic data was respectively. Then analyzed the effects of individual cognitive style on media using.

The answers were recorded as follows.

Table 1. Answers of group A(Field Dependent)

\begin{tabular}{lllll}
\hline Answers & Newspaper & Radio & Television & Internet \\
\hline 1st & 50 & 3 & 113 & 154 \\
2nd & 92 & 3 & 79 & 146 \\
3rd & 94 & 87 & 120 & 119 \\
4th & 84 & 227 & 8 & 1 \\
\hline
\end{tabular}

Table 2. Answers of group B(Field Independent)

\begin{tabular}{lllll}
\hline Answers & Newspaper & Radio & Television & Internet \\
\hline 1st & 27 & 0 & 141 & 152 \\
2nd & 64 & 2 & 110 & 144 \\
3rd & 132 & 105 & 60 & 23 \\
4th & 97 & 213 & 9 & 1 \\
\hline
\end{tabular}

12 volunteers tried to change their media using habit and individual cognitive style

We selected 6 volunteers from each group for further experiment. In three months, they attempted to use different media from their questionnaire ,in order to change their habits of media using.For embedded figure test again at the end of the three months, checked whether it can change the individual cognitive style.

\section{The Analysis of Questionnaire Survey}

At first, we contrast the preferred option distribution of two groups, as shown in table 3: preference distribution of two groups.

Table 3. Preference distribution of two groups

\begin{tabular}{lllll}
\hline Group & Newspaper & Radio & Television & Internet \\
\hline $\begin{array}{l}\text { A(Field } \\
\begin{array}{l}\text { Dependent) } \\
\text { B(Field }\end{array}\end{array}$ & 50 & 3 & 113 & 154 \\
$\begin{array}{l}\text { Independent) } \\
\text { 27 }\end{array}$ & 0 & 141 & 152
\end{tabular}

Then, we do weighted statistical for the chosen conditions in the four medias. If it is the first choice, 
get 4 points, second choice, 3 points. third choice, 2 points. fourth choice, 1 points. The results is shown in table 4: weighted score for selected conditions.

Table 4. Weighted score for selected conditions.

\begin{tabular}{lllll}
\hline Group & Newspaper & Radio & Television & Internet \\
\hline $\begin{array}{l}\text { A(Field } \\
\begin{array}{l}\text { Dependent) } \\
\text { B(Field }\end{array}\end{array}$ & 748 & 422 & 937 & 1093 \\
$\begin{array}{l}\text { Independent) } \\
\text { Ind }\end{array}$ & 429 & 1023 & 1087 \\
\hline
\end{tabular}

We can find such rules from these tables.

\subsection{Network is very attractive for people in two groups.}

Either field dependent or field independent, each has nearly half of the people choosing the network as the preferred choice in media using. While in weighted score, the internet is the highest in both groups.

Strictly speaking, the network is a media integration platform, rather than a pure media. It cater to the pursuit of freedom and fresh in the age of college students, the rich media content has become a preferred use of media. The questionnaire reflect this phenomenon.

Another reason that the network was respected is its multimedia integrated characteristics. No matter what the media using habits, someone can find suit method here.

\subsection{Individual cognitive style affects media using}

The group of field dependent use newspapers than field independent. The television is on the contrary. So is all in the preferences and weighted score. As a recession of the media, the radio is very unpopular with young people, and in the field dependent group, it is selected more than the field independent group.

From the above, individuals with different cognitive styles have a significant influence on the media using. Field dependent people will use stronger participation strong media, such as newspapers and radio. But the field independent people will use weaklier participation media, they can jump out of it at any time, such as television.

\section{The Analysis of Experimental Results}

\subsection{The habits of media using can be changed}

In the three months of the experiment, participants were asked to change the original media habits, try to use more media. For example, the one who liked to read the newspaper were required to watch the news on TV, the one who liked watching TV were required to find a solution to a problem from the newspaper or books.

With the experiments, we found that their media habits were changing slowly. at the beginning ,they could not adapt to the change, then they were used to select the designated media. There were two subjects, which can make according to the choice of experimental design without clear requirements.

\subsection{The wider media using can improve the cognitive efficiency}

When these subjects were accustomed to using more media, we found that the efficiency of learning knowledge, receiving information or solving problem was improved. Especially in solving problems, they had more channels to find the answer, it was more likely to succeed.

\subsection{It is difficult to change cognitive style in the short term}

At the end of the experiment, we taked Embedded Figure Test on the 12 experimental subjects again. There is no significant changes on their individual cognitive style. 
Individual cognitive style is a relatively stable psychological attribute, it is formated by the reasons in many aspects, such as genetic, environmental, education, habits etc.

There is no relevant or not significantly related to cognitive style and intelligence, it is affected mostly by childhood foster solving process attitude in the perception, memory, and the way of expression. Cognitive style is the individual differences in cognitive process, a process variable rather than the contents of the variable. It is stable across time and cross situational consistency, and has characteristics of polar and neutral in value. It is difficult to change cognitive style by changing the media using habits.

\section{Summary}

Through the investigation and experiment, we can find that, although the individual cognitive style is not related to intelligence, but through the influence of media using,it can affect a person's ability of knowledge learning, information processing and problem solving. The media using habits may be form in the long-term living and learning environment and cultivation, significantly influenced by individual cognitive style.

At the same time, media using habits can be changed with the more diverse media use and more rich media environmen. We can change the media habits under the influence of one cognitive style, so as to improve the efficiency of knowledge learning, information processing and problem solving.

What would we do with these conclusions?

First, because the effect to media using of cognitive style, it needs a long process for the new media replacing the old media, and even can not replace completely. We must be fully prepared for the harmonious development of all kinds of media.

Second, the integrated use of multimedia can reduce the cognitive style in some negative impact, such as knowledge learning, information processing and problem solving. It can improve the effect of teaching and communication if we try to use a variety of media. For example, in instruction, developing the multimedia teaching can satisfy different students' learning needs with different individual cognitive styles, so we can improve our teaching efficiency.

Third, for the individual, diversifying the choice of media using can improve the cognitive efficiency of our own, and thus enhance our ability.

\section{References}

[1] Eugene Sadler-Smith, Peter J. Smith, Strategies for accommodating individuals' styles and preferences in flexible learning programmes. British Journal of Educational Technology, 35(4), 395-396, 2004.

[2] Lin Shengdong, Ke Xue, The related research of several tools of field dependent, independent measurement field, Psychological Exploration,1, 59, 2011.

[3] Wo Jianzhong, Wen Li, Zhou Shaoxian, Progress in the study of cognitive style theory, Studies of Psychology and Behavior, 4, 598, 2004. 